Valerie A. Lazzell MD, Alison S. Carr MB BS FRC Anaes, Jerrold Lerman MD FRCPC, Federick A. Burrows MD FRCPC Robert E. Creighton MD FRCPC

\title{
The incidence of masseter muscle rigidity after succinylcholine in infants and children
}

To determine whether the incidence of masseter muscle rigidity is affected by the anaesthetic induction sequence, we prospectively studied for ten months the anaesthetic course in 5,641 infants and children who received muscle relaxation to facilitate tracheal intubation. The anaesthetic induction sequence consisted of intravenous sodium thiopentone (STP) $5 \mathrm{mg} \cdot \mathrm{kg}^{-1}$ alone, halothane induction alone $1-4 \%$, or halothane followed by STP. Inhalational inductions with halothane included nitrous oxide and oxygen. Tracheal intubation was facilitated by either intravenous succinylcholine (Sch) at least $1.5 \mathrm{mg} \cdot \mathrm{kg}^{-1}$ or by a non-depolarizing muscle relaxant. The induction sequence and all episodes of MMR were recorded. Ninety percent of the patients received $S c h$ and $10 \%$ received a non-depolarising agent. Of those who received Sch, $88 \%$ (5,064 patients) were anaesthetised with STP and 12\% (607 patients) were anaesthetised with halothane alone or halothane followed by STP. Masseter muscle rigidity was defined clinically by the transient inability to distract the mandible from the maxilla such that the mouth could not be opened or could only be opened with force. No children anaesthetised with STP followed by Sch developed MMR. One child (0.9\%) developed MMR after halothane and Sch and two developed MMR after halothane, STP and Sch (0.4\%). The incidence of MMR after Sch was less with STP than with halothane alone or with halothane and

\section{Key words}

ANAESTHESIA: paediatric;

HYPERTHERMIA: malignant;

NEUROMUSCULAR RELAXANT: succinylcholine.

From the Department of Anaesthesia and the Research Institute, The Hospital for Sick Children, University of Toronto, Toronto, Ontario. Presented in part, at the annual meeting of the American Society of Anesthesiologists, New Orleans, LA, October 1989.

Address correspondence to: Dr. Jerrold Lerman, Department of Anaesthesia, The Hospital for Sick Children, 555 University Avenue, Toronto, Ontario, Canada M5G 1X8. Accepted for publication 3rd March, 1994.
STP $(P<0.025)$. The peak $C P K$ values in the three children who developed $M M R$ were $17,580 \mathrm{IU} \cdot L^{-1}$ after halothane and Sch, and 7,280 IU ${ }^{-1}$ and 3,273 IU ${ }^{-1}$ afier halothane, STP and Sch. There was no evidence of $M H$ reactions in these patients. No child developed malignant ventricular arrhythmias or cardiac arrest after Sch or a non-depolarising neuromuscular relaxant. There were no episodes of succinylcholine apnoea. We conclude that MMR is less likely to occur following STP and Sch than after halothane and Sch.

Cette travail vise à déterminer si la séquence de linduction de l'anesthésie a une influence sur lincidence de la rigidité du muscle masséter (RMM). A cet effet, nous avons mené une étude prospective de dix mois portant sur l'anesthésie de 5,641 nourrisons et enfants au cours de laquelle ils ont reçu un relaxant musculaire pour faciliter lintubation. A linduction, la séquence anesthésique était constituée de thiopentone sodique (TPS) $5 \mathrm{mg} \cdot \mathrm{kg}^{-1}$ seul, dhalothane seul à $1-4 \%$, ou dhalothane suivi de TPS. Linduction inhalatoire à l'halothane comprenait du protoxyde d'azote et de l'oxygène. Lintubation trachéale a été facilitée soit par de la succinylcholine intraveineuse (Sch) $1,5 \mathrm{mg} \cdot \mathrm{kg}^{-1}$ ou plus, soit par une relaxant non dépolarisant. La séquence dinduction et tous les épisodes de RMM ont été enregistrés. Quatre-vingt-six pour cent des patients ont reçu de la Sch et $10 \%$ un non dépolarisant. Parmi ceux qui ont reçu de la Sch, 88\% (5064 patients) ont été anesthésiés avec du TPS et $12 \%$ (607) avec de l'halothane seul ou l'halothane suivi de TPS. La rigidité du muscle masséter était définie comme une inhabilité transitoire de séparer la mandibule du maxillaire de façon telle que la bouche ne pouvait être ouverte ou ne pouvait l'être que par la force. Aucun des enfants anesthésiés avec TPS suivi de Sch n'a présenté de RMM. Un enfant $(0,9 \%)$ a developpé de la RMM après halothane et Sch et deux ont développé de la RMM après halothane, TPS and Sch $(0,4 \%)$. Lincidence de RMM après Sch a été moins élevée avec TPS qu'avec halothane seul ou halothane et TPS $(P<0,025)$. Les valeurs maximales des $C P K$ chez les trois enfants qui ont développé de la RMM étaient de $17580 \mathrm{UI} \cdot L^{-1}$ après halothane et Sch, et $7280 \mathrm{UI} \cdot L^{-1}$ et $3273 U I^{\prime} L^{-1}$ après halothane, TPS et Sch. On n'a pas 
trouvé de signes d'HM chez ces enfants. Aucun des enfants n'a développé d'arrythmies ventriculaires malignes ou d'arrêt cardiaque après Sch ou le non dépolarisant. Il n'ya pas eu d'épisode d'apnée à la succincylcholine. Nous concluons que la RMM est moins susceptible de se produire après TPS et Sch qu'après halothane et Sch.

Several studies have reported the incidence of masseter muscle rigidity (MMR) in children to be between $0.3 \%$ and $1.08 \% .^{1-4}$ These data were based on retrospective chart reviews of infants and children who were anaesthetised with halothane and paralyzed with succinylcholine (Sch). It has been our experience in over 400,000 anaesthetics induced with intravenous thiopentone (STP) and followed with Sch that complications attributable to Sch including MMR were much less frequent than those reported in the literature. To address our impressions, we prospectively monitored events during the induction of anaesthesia and immediately afterwards in over 5,000 infants and children in our institution over a ten-month period. Events sought were the presence of MMR, any episodes of malignant ventricular arrhythmias or cardiac arrest, and any episodes of succinylcholine apnoea.

\section{Methods}

This study was approved by the human subject review committee. Infants and children who were scheduled for elective non-cardiac surgery requiring tracheal intubation were studied. Children were excluded from the study if there was a history of malignant hyperthermia, a muscle disorder, a cholinesterase deficiency or a contraindication to intubation.

The anaesthetic induction sequence was not randomised but was chosen by the attending anaesthetist. Demographic data were collected. The induction sequence and all events occurring during the pre-induction period were recorded.

All children received a preoperative anaesthetic assessment. Monitoring included ECG, non-invasive blood pressure, arterial oxygen saturation, end-tidal carbon dioxide concentration, inspired oxygen concentration, endtidal halothane concentration and temperature. The extent of neuromuscular blockade was not routinely assessed at induction of anaesthesia. Children were anaesthetised by one of three induction sequences: intravenous thiopentone (STP) $5 \mathrm{mg} \cdot \mathrm{kg}^{-1}$ alone, halothane $1-4 \% / \mathrm{ni}-$ trous oxide/oxygen by inhalation alone or the combination of halothane/nitrous oxide/oxygen initially followed by STP. Atropine $0.02 \mathrm{mg} \cdot \mathrm{kg}^{-1} \dot{\mathrm{i}}$ was given before succinylcholine. Tracheal intubation was facilitated by administration intravenously of either succinylcholine (at least $1.5 \mathrm{mg} \cdot \mathrm{kg}^{-1}$ ) or a non-depolarising muscle re-
TABLE I

\begin{tabular}{|c|c|c|c|}
\hline Induction & $\begin{array}{l}\text { Non-Strabismus } \\
\text { surgery }\end{array}$ & $\begin{array}{l}\text { Strabismus } \\
\text { surgery }\end{array}$ & Total \\
\hline \multicolumn{4}{|c|}{ Intubation with succinylcholine } \\
\hline STP & 4003 & 454 & 4457 \\
\hline H/STP & 407 & 89 & 496 \\
\hline $\mathrm{H}$ & 102 & 9 & 111 \\
\hline Total & 4512 & 552 & 5064 \\
\hline \multicolumn{4}{|c|}{ Intubation with non-depolarising muscle relaxant } \\
\hline STP & 447 & 31 & 478 \\
\hline $\mathrm{H} / \mathrm{STP}$ & 49 & 3 & 52 \\
\hline $\mathrm{H}$ & 47 & $\underline{\mathbf{0}}$ & 47 \\
\hline Total & 543 & 34 & 577 \\
\hline Grand total & 5055 & 586 & 5641 \\
\hline
\end{tabular}

$\mathrm{H}=$ halothane, STP $=$ thiopentone.

laxant (pancuronium, vecuronium and atracurium in intubating doses). ${ }^{5-7}$

Masseter muscle rigidity was defined clinically by the transient inability to distract the mandible from the maxilla such that the mouth could not be opened or could only be opened with force. ${ }^{8}$ The diagnosis of MMR was made by the supervising anaesthetist and confirmed by a second staff anaesthetist immediately available. If MMR did occur, the anaesthetic course and any signs of malignant hyperthermia ( $\mathrm{MH}$ ) were recorded. Blood gas analysis and the serum concentration of creatine phosphokinase (CPK) were determined in children who developed MMR. Serum CPK was measured at 6,12 and $24 \mathrm{hr}$ after surgery in these children. Urine was not obtained for myoglobin analysis. Dantrolene was administered only if an $\mathrm{MH}$ reaction occurred.

Statistical significance $(P<0.05)$ was determined using Fisher's exact test for proportions. Maximum longrun risks were also calculated. ${ }^{9}$

\section{Results}

Five thousand six hundred and forty-one infants and children were enrolled in the study (Table I). Five thousand and sixty-four patients $(90 \%)$ received Sch prior to intubation. Of these, $4,457(88 \%)$ received only STP prior to Sch, while the remainder, 607 (12\%) received halothane. Of those who received halothane before Sch, 111 received halothane alone and 496 received halothane followed by STP immediately before succinylcholine.

Five hundred and seventy-seven patients (10\%) underwent tracheal intubation after the administration of a nondepolarising muscle relaxant. None of the children who received a non-depolarising relaxant experienced MMR and none developed malignant ventricular arrythmias or a cardiac arrest during induction. 
TABLE II Incidence of masseter muscle rigidity (MMR)

\begin{tabular}{llll}
\hline $\begin{array}{l}\text { Anaesthetic } \\
\text { technique }\end{array}$ & $\begin{array}{l}\text { Number of } \\
\text { patients }\end{array}$ & $\begin{array}{l}\text { Number (\%) } \\
\text { with MMR }\end{array}$ & CPK $\left(I U \cdot L^{-1}\right)^{*}$ \\
\hline H/STP/Sch & 496 & $2(0.4 \%)$ & $7,280,3,273$ \\
H/Sch & 111 & $1(0.9 \%)$ & 17,580 \\
\hline
\end{tabular}

$\mathrm{H}=$ halothane, STP $=$ thiopentone, $\mathrm{Sch}=$ succinylcholine.

*Maximum postoperative CPK.

Three episodes of MMR occurred in children who had received halothane prior to Sch for an incidence of $0.5 \%$ (Table II). Two of these occurred in children who had received halothane followed by STP and Sch $(0.4 \%$ incidence) and one occurred in a child who had received halothane alone before Sch ( $0.9 \%$ incidence). The child who developed MMR after halothane and Sch was scheduled for hypospadias repair and the two children who developed MMR after halothane, STP and Sch, for tonsillectomy, adenoidectomy, and bilateral myringotomy in one case and for bilateral inguinal herniotomies in the other. The ages of the three children who developed MMR were $4.5 \mathrm{yr}, 5 \mathrm{yr}$ and $7 \mathrm{yr}$. Preoperatively, these children were not considered MH susceptible and exhibited no signs of neuromuscular disease. After MMR was diagnosed, the tracheas were intubated and anaesthesia was continued. One anaesthetic was continued with halothane and two were continued with non-triggering agents. There was no evidence of a malignant hyperthermia reaction during the anaesthetic in these three children. Arterial blood gas analyses obtained after MMR were within normal limits in all three children. All children were monitored with hourly vital signs for $24 \mathrm{hr}$ after surgery in hospital. The peak serum concentrations of CPK obtained during the $24 \mathrm{hr}$ after surgery in the three children are shown in Table II (normal values are $<255 \mathrm{IU} \cdot \mathrm{L}^{-1}$ for children $<12 \mathrm{yr}$ ). There was no evidence of an MH reaction in the postoperative period.

Five hundred and eighty-six patients were scheduled for strabismus surgery. Of these, 89 children were anaesthetised with halothane followed by STP and Sch, and in nine children, anaesthesia was induced with halothane followed by Sch. There were no episodes of MMR or signs of $\mathrm{MH}$ in any of the children scheduled for strabismus surgery.

No child developed succinylcholine apnoea, malignant ventricular arrhythmias or cardiac arrest following intravenous succinylcholine.

\section{Discussion}

The role of Sch in the genesis of MMR is welldocumented. ${ }^{10}$ In the presence of Sch, MMR may occur; in its absence, MMR is unlikely. In this study we found that the incidence of MMR after the combination of STP and Sch was less than after halothane and Sch, with or without the presence of STP $(P<0.025)$. Our data suggest that the combination of halothane and Sch may precipitate MMR in children.

In our study, none of the 4457 children anaesthetised with STP and Sch developed evidence of MMR. Even though these data may lead one to conclude that MMR does not occur after STP and Sch, reports and anecdotes exist that dispute this notion. ${ }^{11-13}$ Nonetheless, we may ask what is the likelihood of MMR after the combination of STP and Sch in the whole population at risk. The upper $95 \%$ confidence limit of the maximum long-run risk of MMR after STP and Sch that is compatible with an incidence of $0 / 4457$ is $0.07 \%$ or $7 / 10,000 .{ }^{9}$ Hence, our data indicate that while MMR after STP and Sch is rare, it is not beyond possibility.

We found that the incidence of MMR when anaesthesia was induced with STP was 2.25 . fold less than when anaesthesia was induced with halothane and Sch (Table I), although this is consistent with the known effects of STP on the incidence of cardiac arrhythmias ${ }^{14}$ and on delaying the onset of $\mathrm{MH}$ reactions. ${ }^{15}$ However, the difference between STP and halothane and Sch did not achieve statistical significance. We attribute this to a disparity in the sample size between the two groups. We were limited in the sample size of the halothane and Sch group as this combination is used infrequently in our institution. To adjust for the limited sample size of this group, the size of the halothane/STP/Sch sample would need to exceed 20,000 patients to approach even a 50\% power in detecting a difference in MMR between the two groups. Here, the sample size of children who received the latter induction sequence, four hundred and ninety-six, was insufficient. A larger study is needed to establish whether a statistically significant effect of STP against MMR after a halothane and Sch induction exists.

In a retrospective study, the incidence of MMR after halothane and Sch in children undergoing strabismus surgery was reported to be $2.8 \%{ }^{2}$ These data are not consistent with our findings in which none of the 586 children undergoing strabismus surgery developed MMR. However, 454 children $(77 \%)$ in our study received STP and Sch and only 98 patients $(17 \%)$ received halothane followed by either Sch alone or by STP and Sch. If the data from the published study ${ }^{2}$ held true for our patient population, we would have expected three children to develop MMR after halothane and Sch. This was not the case. Plausible explanations for this discrepancy include a different population undergoing strabismus surgery, an overestimation of the incidence of MMR in the published study of children with strabismus ${ }^{2}$ 
or our failure to detect episodes of MMR. The last explanation in improbable since this study was designed to detect prospectively and report all episodes of MMR. The first two explanations together or in part may explain the difference between the two studies.

What is the likelihood of a positive muscle biopsy for MH in children who develop MMR after thiopentone and succinylcholine compared to after halothane and succinylcholine? In a study by Christian et al. ${ }^{13}$ the incidence of malignant hyperthermia susceptibility (MHS) in children who developed MMR after an intravenous induction including Sch was twice that in children who presented with MMR after an inhalational induction and intravenous Sch. This suggests that the combination of halothane and Sch yields a far greater incidence of MMR than that which can be accounted for by MHS. Thus it would seem reasonable to treat episodes of MMR after halothane and Sch conservatively. In contrast, these data suggest that episodes of MMR after an intravenous induction and Sch may be more likely to yield a positive muscle biopsy for MH. This is not surprising after an intravenous induction and Sch as MMR occurred in response to a single trigger, Sch, and occurred despite the presence of a barbiturate. ${ }^{15}$ Although MMR occurs rarely after STP and Sch, if it were to occur, these data suggest that MMR should be aggressively investigated and the family counselled for MHS.

Previous studies have suggested that $50-60 \%$ of patients who develop MMR are proved to be MH susceptible (MHS) on the basis of muscle biopsy. ${ }^{11,12}$ The incidence of 1:200 for MHS is at odds with the historical incidence of $\mathrm{MH}$ based on the incidence of $\mathrm{MH}$ reactions in children, 1:15,000 ${ }^{23}$ There are several plausible explanations for this difference. First, MMR may be a form fruste of $\mathrm{MH}$ that is far more common than $\mathrm{MH}$ and less likely to lead to an $\mathrm{MH}$ reaction, but is indistinguishable from $\mathrm{MH}$ on the basis of a muscle biopsy. Second, muscle biopsies for MH may yield false-positive results in children. In support of this notion, Larach reported false-positive biopsy rates of 17-38\% depending on the criteria used for the caffeine contracture test. ${ }^{24}$ Furthermore, genetic mapping of the MH defect on chromosome 19 (the ryanodine receptor gene ${ }^{25}$ ) has been shown to co-segregate with only some results of the caffeine contracture test. ${ }^{26}$ This too suggests the possibility of false positive muscle biopsy results. These data lead us to conclude that the incidence of $\mathrm{MH}$ in the population as determined by muscle biopsy is far more common than that predicted by the historical incidence of $\mathrm{MH}$ reactions in the population.

Three children in this study developed isolated MMR without evidence of an MH reaction. This is consistent with previously published reports where MMR did not herald MH. ${ }^{1,24}$ Although the families of the three children who developed MMR have been counselled, we have not encouraged the children to undergo muscle biopsy for MH. We have advised the parents that their children experienced an unusual response to halothane and Sch and that the children should wear a medic-alert bracelet stating this risk.

If MMR is not a herald of MH, why does it occur? Van Der Spek observed a significant increase in stiffness of the muscles influencing mouth opening after administration of succinylcholine. ${ }^{16-18}$ Other studies showed that the resting tension in the masseter muscle increased in a dose-related manner as succinylcholine blocked neuromuscular function. ${ }^{19,20}$ The increase in resting tension appeared to be a physiological action of succinylcholine and despite considerable interindividual variability, the effect was clearly dose-dependent. Plumley et al. reported that the time (mean \pm standard deviation) from injecting succinylcholine to the maximum increase in resting tension of the masseter was 15 to $70 \mathrm{sec}$, while the duration of the effect was 10 to $120 \mathrm{sec} .{ }^{19}$ From these data, it has been suggested that perhaps masseter spasm may be an exaggerated form of a normal pharmacological effect of succinylcholine. ${ }^{19}$ Another study investigated the incidence and degree of change in jaw tone following different doses of succinylcholine in adults after induction of anaesthesia with thiopentone. ${ }^{21}$ Results indicated that an increase in the tone of the jaw muscles may be a normal response after succinylcholine. Thus, in some children, MMR may be an exaggerated form of a normal response to a pharmacological effect of succinylcholine.

Creatine phosphokinase estimations were increased in the first $24 \mathrm{hr}$ after anaesthesia in all three children who developed MMR in our study. These results obtained are similar to those reported in cases of MMR in other studies. ${ }^{1,2}$ Surgical trauma can lead to an increase in postoperative CPK estimations postoperatively. The children who experienced MMR in our study had surgical procedures with minimal tissue damage and while it is possible that surgical trauma was the cause of the increased CPK estimations, it is improbable in these cases.

None of the 5,064 infants and children who received intravenous succinylcholine developed succinylcholine apnoea. No children in our study developed malignant ventricular arrhythmias or cardiac arrest. Furthermore, at The Hospital for Sick Children, neuromuscular blockade has been established with succinylcholine in hundreds of thousands of infants, children and adolescents without a single death attributable to succinylcholine. ${ }^{27}$ At the Hospital for Sick Children, succinylcholine continues to be used routinely to facilitate tracheal intubation in infants, children and adolescents.

In summary, we found that $0.5 \%$ of infants and chil- 
dren anaesthetised with halothane and paralysed with Sch developed MMR. In contrast, none of the children who received STP and Sch developed MMR $(P<0.025)$. These data suggest that MMR is more likely to occur in the presence of halothane and Sch than STP and Sch. No cases of cardiac arrest or malignant ventricular arrhythmia occurred in infants and children who received succinylcholine. We conclude that the combination of intravenous thiopentone and succinylcholine is associated with a very small incidence of MMR and is safe for the induction of anaesthesia in infants and children.

\section{Acknowledgments}

We thank all of the staff, fellows and residents in the Department of Anaesthesia for their assistance in completing this study.

\section{References}

1 Schwartz L, Rockoff MA, Koka BV. Masseter spasm with anesthesia: incidence and implications. Anesthesiology 1984; 61: 772-7.

2 Carroll JB. Increased incidence of masseter spasm in children with strabismus anesthetised with halothane and succinylcholine. Anesthesiology 1987; 67: 559-61.

3 Littleford JA, Patel LR, Bose, Cameron CB, MCKillop C. Masseter muscle spasm in children: implications of continuing the trigger anesthetic. Anesth Analg 1991; 72 : $151-60$.

4 Kosko JR, Brandom BW. Chan KH. Masseter spasm and malignant hyperthermia: a retrospective review of a hospital-based pediatric otolaryngology practice. Int J Ped Otorhinolaryngol 1992; 23: 45-50.

5 Goudsouzian NG, Ryan IF, Savarese JJ. The neuromuscular effects of pancuronium in infants and children. Anesthesiology 1974; 41: 95-8.

6 Ferres CI, Crean PM, Mirakhur RK. An evaluation of Org NC45 (vecuronium) in paediatric anesthesia. Anaesthesia 1983; 38: 943-7.

7 Goudsouzian NG, Liu LMP, Gionfriddo M, Rudd GD. Neuromuscular effects of atracurium in infants and children. Anesthesiology 1985; 62: 75-8.

8 Rosenberg $H$. Trismus is not trivial (Editorial). Anesthesiology 1987; 67: 453-5.

9 Hanley $J A$, Lippman-Hand $A$. If nothing goes wrong, is everything all right? Interpreting zero numerators. JAMA 1983; 249: 1743-5.

10 Saddler $J M$. Jaw stiffness - an ill understood condition (Editorial). Br J Anaesth 1991; 67: 515-6.

11 Rosenberg H, Fletcher JE. Masseter muscle rigidity and malignant hyperthermia susceptibility. Anesth Analg 1986; 65: 161-4.

12 Donlon JV, Newfield P, Sreter F, Ryan JF. Implications of masseteric spasm after succinylcholine. Anesthesiology 1978; 49: 298-301.

13 Christian AS, Ellis FR, Halsall PJ. Is there a relationship between masseteric muscle spasm and malignant hyperthermia? Br J Anaesth 1989; 62: 540-4.

14 Badgwell JM, Cunliffe M, Lerman J. Thiopental attenuates dysrhythmias in children: a comparison of thiopental and halothane anesthetic inductions. Texas Medicine 1990; 86: 36-8.

15 Gronert GA, Milde JH. Variations in onset of porcine malignant hyperthermia. Anesth Analg 1981; 60: 499-503.

16 Van Der Spek AFL, Fang WB, Ashton-Miller.JA, Stohler CS, Carlson DS, Schork MA. The effects of succinylcholine on mouth opening. Anesthesiology 1987; 67: 459-65.

17 Van Der Spek $A F L$, Fang WB, Ashton-Miller JA, Stohler $C S$, Carlson DS, Schork MA. Increased masticatory muscle stiffness during limb muscle flaccidity associated with succinylcholine administration. Anesthesiology 1988; 69: 11-6.

18 Van Der Spek AFL, Reynolds PI, Ashton-Miller JA, Stohler CS, Schork MA. Differing effect of agonist and antagonist muscle relaxants on cat jaw muscles. Anesth Analg 1989; 69: 76-80.

19 Plumley MH, Bevan JC, Saddler JM, Donati F, Bevan $D R$. Dose-related effects of succinylcholine on the adductor pollicis and masseter muscles in children. Can $\mathbf{J}$ Anaesth 1989; 37: 15-20.

20 Saddler JM, Bevan JC, Plumley MH, Polomeno RC, Donati $F$, Bevan $D R$. Jaw tension after succinylcholine in children undergoing strabismus surgery. Can J Anaesth 1989; 37: 21-5.

21 Leary NP, Ellis FR. Masseteric muscle spasm as a normal response to suxamethonium. Br J Anaesth 1990; 64: 488-92.

22 Flewellen EH, Nelson TC. Halothane-succinylcholine induced masseter spasm: indicative of malignant hyperthermia susceptibility? Anesth Analg 1984; 63: 693-7.

23 Britt HA, Kalow $W$. Malignant hyperthermia: a statistical review. Can Anaesth Soc J 1970; 17: 293-315.

24 Larach MG, Landis JR and the North American Hyperthermia Registry. Sources of variation in false positive diagnostic rates of malignant hyperthermia using the North American Protocol for caffeine halothane p. contracture testing (Abstract). J Neurol Sci 1990; 98(suppl): 521.

25 MacLennan $D H$, Duff $C$, Zorzato $F$, et al. Ryanodine receptor gene is a candidate for predispositon to malignant hyperthermia. Nature 1990; 343: 559-61.

26 Allen G, MacKenzie A, Lahey D, et al. A comparison of the caffeine halothane contracture test with molecular genetics diagnosis of malignant hyperthermia. Anesthesiology 1990; 73: A711.

27 Lerman J, Berdock SE, Bissonnette B, et al. Succinylcholine warning (Letter). Can J Anaesth 1994; 41: 165. 